\title{
Social dominance and learning in the domestic chicken'
}

DOUGLAS K. CANDLAND AND DANIEL H. CONKLYN, ${ }^{2}$ BUCKNELL UNIVERSITY, Lewisburg, Pa. 17837

It has been suggested that rank on the social dominance order is related to "intelligence" or the ability to learn of the domestic chicken. When dominance is assessed by pair comparison procedures and learning is measured by performance in a 3 cul-maze in Rhode Island Reds raised either communally or in social isolation for any of three durations $(15,30$, or 81 days), dominance rank is unrelated to learning ability.

The reports of Schjelderup-Ebbe $(1922,1935)$ and Murchison (1935 et seq) established the observation that flocks of chickens maintain dominance, or "pecking" orders as they are often, but inappropriately, called, and prompted investigations of dominance and status relationships in a number of species and investigations of the parameters of variables affecting the dominance order of domestic chickens. (For reviews, see Allee, 1938; Collias, 1944, 1950; Guhl, 1962.) The 1923 report of Katz \& Toll $^{3}$ is often cited as evidence for the statement that "intelligence" and dominance rank are positively correlated. Advances in methodology since their pioneer work suggest the utility of re-examining this reported relationship. Katz \& Toll reported a high, positive correlation between intelligence and dominance rank when the former was measured by the ability to consistently peck at every third piece of grain and the latter by post-factum recall. In the present study, dominance was assessed by a full pair comparison procedure with repetition to permit assessment of reliability. Learning ability was measured by performance in a 3 cul-maze. The maze was selected as the learning task mainly because it is one of the few suitable tests for cross-species comparisons and because comparative data are available on this test for a variety of species. Nevertheless, it is noteworthy that learning to avoid culs is not a common behavior of the domestic chicken in nature and that there is no reason to suspect outstanding performance on this, a task requiring behavior of little survival value to the domestic chicken. Because the domestic chicken is basically an aggregative bird, birds were raised both in flocks and in social isolation from one another for varying periods of time in order to determine if these factors influence the course of learning or the reliability of the dominance relationships.

Subjects and Procedure. From hatching, 62 Rhode Island Red roosters were raised either in individual cages ( $14 \times 16 \times 16$ in. high) or in communal living accommodations ( $14 \times 36 \times 16$ in. high) with between 8-12 birds in each flock. Birds were maintained under either of these conditions to different ages $(15,30$ or 81 days). At the appropriate age, food was removed for $24 \mathrm{~h}$ (water was retained) until weight decreased to between 87 and $91 \%$ of predeprivation weight.

Dominance rank was assessed in a circular arena $18 \mathrm{in}$. in diameter with a floor of $1 / 2 \mathrm{in}$. wire mesh and walls $24 \mathrm{in}$. high composed of aluminum roofing. The center of the arena held a foodcup $(1 \times 1 / 2 \times 1$ in.) filled with the usual diet of purina Starter (15 and 30 day birds) or Grower ( 81 days), but which was covered by a solid gate that bisected the arena and covered the foodcup. A trial consisted of placing two birds from the same group in the arena, one on each side of the gate. When the birds appeared to have recovered from handling, the gate was raised to allow access to the cup. Combative behavior was common. Two Os recorded the amount of time that each bird was at the cup during the 3-min test period. The bird retaining control of the cup for the longest time was considered dominant on that trial. Each bird was paired with each other bird in a prearranged random order, so that with a flock of 10 birds, 45 contests were held. The number of wins was converted to $z$-scores (for a description of method, see Candland, 1968). This procedure was repeated on the following day in order to assess the reliability of the order. All correlations (rank order) were above 0.89 and were significant $(<.05)$. It is noteworthy that birds raised in social isolation showed orders as reliable as those reared in flocks.

On the third day each bird began the learning task by being placed in the starting hox of the maze. The maze formed a rectangle $2 \times 6 \times 2$ fi high,
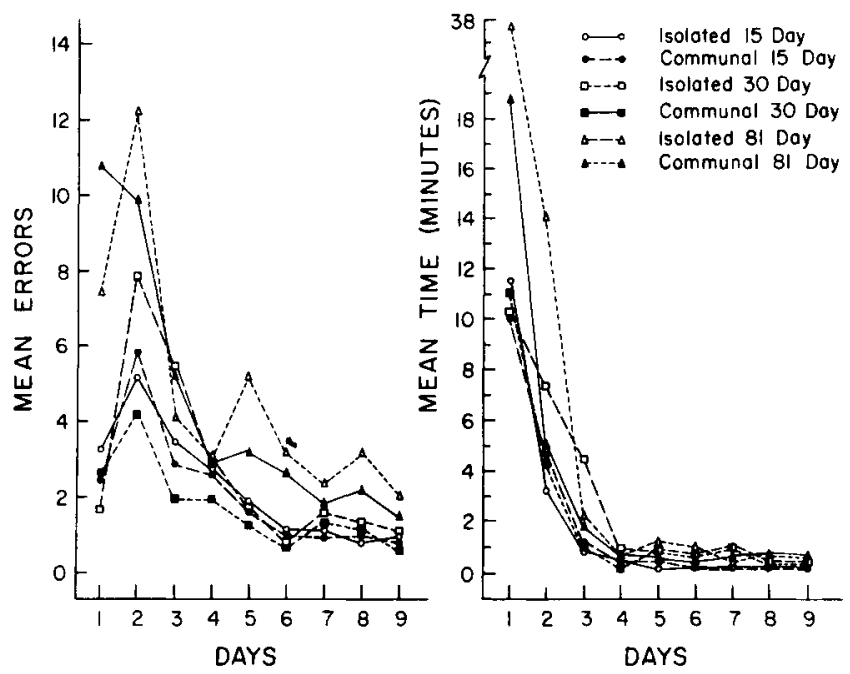

Fig. 1. Mean errors (left panel) and mean running time in minutes (right panel) as a function of age, rearing condition, and test days.

painted black, with $1 / 2$ in. wire mesh floor and a plastic covering to diffuse light. Upon completing the maze, the bird was allowed to eat the normal diet in the goal box for $20 \mathrm{sec}$. Three trials were given each day for nine consecutive days. Birds not moving within $\mathbf{4 0}$ min were returned to their cage and tested the following day. This freezing response occurred in $42 \%$ of the birds, but rarely after the first day of testing (Candland, Nagy, \& Conklyn, 1962). At the conclusion of the series, a re-assessment of the dominance order was made following the procedure described above. The reliability between the initial dominance tests and the final assessment was high for all groups (lowest, $0.95, \mathrm{p}<.01$ ).

Results. Figure 1 shows the mean number of errors and the mean amount of time spent in the maze by all age groups as a function of rearing conditions. Older birds spend more time completing the maze trials and commit more errors than younger ( 15 and 30 days) birds. The increase in errors on the second test probably reflects exploratory behavior after the emotionality associated with placement in the novel maze has dissipated following the first day of testing. The difference as a function of age is more likely to be motivational than to result from different ontogenetic learning capacities, since it is likely that deprivation to approximately $90 \%$ body weight is more severe for younger chickens than older (Lakatos, Stoltz, \& Moyer, 1966).

Correlations were run between dominance order and (a) weight on the day of dominance test, (b) number of errors in maze, (c) amount of time in maze, and between number of errors and amount of time, for all age groups, and for all rearing conditions. With one exception (dominance order and total errors for 30-day old, communally raised, birds, $r=0.83, p<.01$ ) none of the correlations between dominance order and either errors or time approach significance. Indeed they tend to be negative, implying that the bird who completes the maze with fewer errors or in less time is likely to be lower on the dominance rank.

The results demonstrate that social dominance, as measured by a suitable scaling technique, is not related to maze-learning; or, conversely, whatever factors are responsible for differences in speed and quality of such learning, position on the dominance order is not among them.

\section{REFERENCES}

ALLEE, W. C. The social life of animals. Abelard-Schuman, 1938. [A revised edition; Cooperation among animals with human implications, Abelard-Schuman, 1951, was published under the title. The social life of animals, Beacon, 1958.1 
CANDLAND, D. K. Psychology: the experimental approach. New York: McGraw-Hill, 1968.

CANDLAND, D. K., NAGY, Z. M., \& CONKLYN, D. H. Emotional behavior in the domestic chicken (White Leghom) as a function of age and developmental environment. J. comp. physiol. Psychol, 1962, 56, 1069-1073.

COLLIAS, N. E. Aggressive behavior among vertebrate animals. Physiol. Zool $1944,17,83-123$.

COLLIAS, N. E. Some variations in grouping and dominance patterns among birds and mammals. Zoologica, 1950, 35, 97-119.

GUHL, A. M. The behavior of chickens. In E. S. E. Hafez (Ed.), The behaviour of domestic animals. Baltimore: Williams and Wilkins, 1962.

KATZ, D., \& TOLL, A. Die Messung von Charakter und Begabungsunterscheiden bie Tieren. (Versuch mit Hühnern). Z. Psychol, 1923, 93, 287-316.

LAKATOS, R. J., STOLTZ, C., \& MOYER, R. S. Effects of deprivation procedures on consummatory motivation in the domestic chicken. $J$. genet.
Psychol, 1966, 109, 231-239.

MURCHISON, C. The experimental measurement of a social hierarchy in Gallus domesticus. I. "The direct identification and direct measurement of social reflex No. 2." J. gen. Psychol, 1935, 12, 3-39. [Remaining papers in this series are: J. soc. Psychol., 1935, 6, 3;. J. genet. Psychol., 1935, 46, 76; J. gen. Psychol., 1935, 12, 296; J. soc. Psychol., 1935, 6, 172.]

SCHJELDERUP-EBBE, T. Beitrage zur Socialpsychologie des Haushuhns. $Z$. Psychol, 1922, 88, 225-252.

SCHJELDERUP-EBBE, T. In C. Murchison (Ed.), Handbook of social psychology. Worcester, Mass.: Clark Univ. Press, 1935.

\section{NOTES}

1. Work performed under MH 06988-04 from the National Insitute of Mental Health, U. S. Public Health Service, to the first author.

2. Now with Armstrong Cork Company, Macon, Georgia.

3. An English translation of the study is available upon request to the first author. 